\title{
Mechanical properties of kenaf fibrous pulverized fuel ash concrete
}

\author{
Norazura Mizal Azzmi ${ }^{1,2}$, Jamaludin Mohamad Yatim ${ }^{1 *}$, Hazlan Abdul Hamid ${ }^{1}$, \\ Azmahani Abdul Aziz ${ }^{1}$, Adole Michael Adole ${ }^{1}$ \\ ${ }^{1}$ School of Civil Engineering, Faculty of Engineering, Universiti Teknologi Malaysia, 81310 Skudai, \\ Johor, Malaysia \\ ${ }^{2}$ Faculty of Architecture, Planning and Surveying, Universiti Teknologi MARA, Malaysia, 32610 Seri \\ Iskandar, Perak, Malaysia
}

\begin{abstract}
The main objective of the experimental work is to identify the mechanical properties of Kenaf Fiber incorporate with Ordinary Portland Cement (OPC) and Pulverised Fuel Ash (PFA) in the mix proportions of concrete. Kenaf Fibrous Concrete (KFC) and Kenaf Fibrous Pulverised Fuel Ash Concrete (KFPC) will be measured on physical and mechanical properties in order to investigate the suitability of this natural fiber as a composite material. A comparison of properties between these two composites will determine the density, workability, compressive, tensile, and flexural strength of the concrete. Eight different mixes with varying percentage of Kenaf fiber were prepared with $30 \mathrm{~N} / \mathrm{mm}^{2}$ strength at 28days ,56 days and 90 days. Short fiber with $25 \mathrm{~mm}$ and $50 \mathrm{~mm}$ length were randomly distribute in composite to enhance the tensile and durability. PFA was obtained by the process of burning in the Power Station Coal Ash at Tanjung Bin, Johor. The unburning powder from the process is called as a PFA generally suitable for cement replacement in the concrete mix. The pozzolanic reaction will improve the adhesion of cement gel, hence increased the properties of concrete in a long-term strength development. The result shows that the inclusion of Kenaf fiber improve tensile strength of composite, furthermore the $25 \%$ PFA mix increase the durability of concrete.
\end{abstract}

\section{Introduction}

The production of many synthetic fibers may contribute to the emission of many $\mathrm{CO}_{2}$ through a chemical process and somehow pollute the environment. It may produce not only carbon dioxide but also nitrous oxide that 310 times more harmful than natural fiber [1]. The kenaf fiber biocomposite in automobile parts reduce reduce $23-24 \%$ energy consumptions and $6-16 \%$ gas emission [2]. This significance effects shows the potential of natural fiber in other field of applications. Synthetic fiber highly ability in mechanical properties, however, give disadvantages in term of the environment. Cement and concrete

\footnotetext{
*Corresponding author: jamaludin@utm.my
} 
were produced massively to fulfill high demands of the construction industry. Cement from limestone caused the production of greenhouse gases and heat release to the environment in the process of calcination to form Ordinary Portland Cement [3].

Green and sustainable material are the main focus of consumer nowadays to provide benefit environmentally and no harm to the earth. The use of the waste product and natural material can save from pollution and contamination to the environment. The main concern of this study is to use waste material from the burning of Power Station Coal Ash and Kenaf plant to introduce a new composite material for the construction industry. This 'greener' concrete has many potentials on restrain load and also durable [4]. Kenaf Fiber was extracted from Kenaf plant that have strong capability in tensile and bending performance.

\subsection{Materials}

\subsubsection{Kenaf Fiber}

Kenaf Fiber comes from a natural plan that provides a good tensile strength. However, natural fiber constituent a cellulose and lignin. In order to make the fiber reliable with concrete, a treatment plan should be considered to remove dirt and untied the polymer bonding of fiber. Its hydrophilic behavior makes the fiber porous and needs to be treated with $5 \%$ sodium Hydroxide $(\mathrm{NaOH})$. This chemical treatment was done to make the fiber free from any cellulose, hemicellulose, lignin, and pectin [5]. This Kenaf fiber was collected from National Kenaf and Tobacco Board at Kelantan, Malaysia.

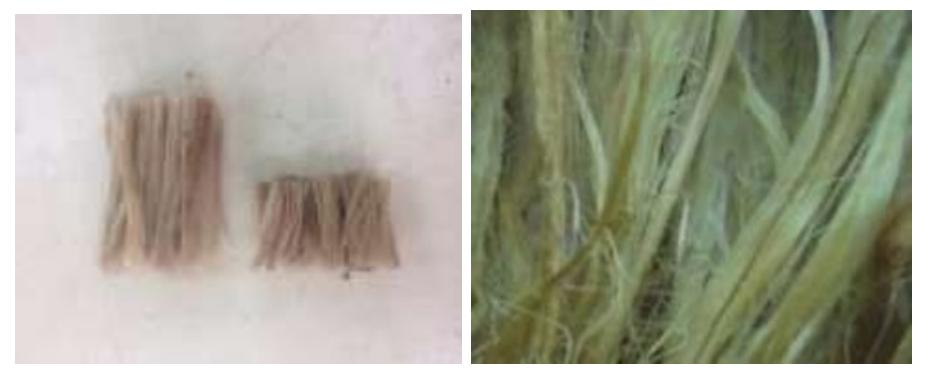

Fig. 1. Kenaf Fiber length of $50 \mathrm{~mm}$ and $25 \mathrm{~mm}$ and fiber treatment.

\subsubsection{Ordinary Portland Cement}

Tasek Portland Cement was used to be the binder of concrete composition. The major chemical composition of Calcium Oxide and Silicon Dioxide are the main composition to form C-S-H gel in the concrete.

\subsubsection{Pulverised Fuel Ash}

The Class F type of Pulverised Fly Ash was used to replace the $25 \%$ of cement in the mix proportion. The main purpose of using Fly Ash is consideration of using a pozzolanic durable material from the aggressive environment. Pulverised Fly Ash Powder was collected from Tanjung Bin Power Plant, Pontian, Johor is class F, whereby the chemical composition of Silica, Alumina and Iron oxide are more than $70 \%$ according to ASTM C618 [6]. The experimental activities using 25\% PFA to replace cement with the total weight of cement. The optimum value of PFA replacement was determined by mechanical 
properties testing, compressive, splitting tensile and flexural properties that have been done before.

\subsubsection{Aggregates}

Crushed granite of $10 \mathrm{~mm}$ size of coarse aggregates has been used in this experimental study. Sieve analysis test was referred to ASTM C136-06 and passing through $4.75 \mathrm{~mm}$ sieve. The sieve analysis for the course and fine aggregate is to determine the gradation of size in cumulative distribution that required in the concrete mix design method.

\subsection{Samples and Mix Proportion}

The objective of this experimental project is finding the mechanical properties Kenaf Fibrous Pulverised Fuel Ash Concrete (KFPC). The used of pozzolans material is a replacement in $25 \%$ weight of cement. There were 162 samples of cubes of $100 \mathrm{~mm}$ by $100 \mathrm{~mm}$ by $100 \mathrm{~mm}$ to indicate the compressive strength. The splitting tensile strength using cylinder mould of $200 \mathrm{~mm}$ height by $100 \mathrm{~mm}$ diameters and $100 \times 100 \times 500 \mathrm{~mm}$ of prism mould for determination of flexural strength. The addition of Rheobuild 1100 superplastisizer is to increase the workability of concrete. Fresh concrete of KFPC needs to use external vibration to ignore segregation of concrete [7].

Table 1. Concrete Mix Proportions Used in The Study of KFPC.

\begin{tabular}{|c|c|c|}
\hline $\begin{array}{c}\text { Constituent } \\
\text { material }\end{array}$ & $\begin{array}{c}\text { Proportions } \\
\left.\text { KFC (kg/m } \mathbf{m}^{\mathbf{3}}\right)\end{array}$ & $\begin{array}{c}\text { Proportions } \\
\text { KFPC }\left(\mathbf{k g} / \mathbf{m}^{\mathbf{3}}\right)\end{array}$ \\
\hline Cement & 463 & 347.3 \\
\hline Fly Ash & - & 115.7 \\
\hline Fine aggregate & 800 & 800 \\
\hline Coarse aggregate & 867 & 867 \\
\hline Water & 250 & 250 \\
\hline $\begin{array}{c}\text { Kenaf Fiber 0.5\%, } \\
0.75 \%, 1 \%, 1.5 \%\end{array}$ & $6,9,12,15$ & $6,9,12,15$ \\
\hline Super plasticizer & 4.63 & 4.63 \\
\hline
\end{tabular}

\section{Test Specimen and Setup}

The initial testing is a fundamental property to investigate how the material will react to the physical force. Fresh concrete density and workability are indicated data to ensure the hardened concrete is compacted homogeneously without bleeding and segregation.

\subsection{Compressive Strength Test}

Compressive strength was executed using the following formula in accordance to BSEN 12390-3:2009.

$$
f_{\mathrm{c}}=\frac{F}{A_{c}}
$$


Where:

$\mathrm{f}_{\mathrm{c}}=$ compressive strength, in $\mathrm{MPa},\left(\mathrm{N} / \mathrm{mm}^{2}\right)$;

$\mathrm{F}=$ maximum load at failure, in $\mathrm{N}$;

Ac $=$ area of the specimen

\subsection{Splitting Tensile Strength Test}

Splitting tensile strength was calculated using the following formula in accordance to ASTM C496M-06

$$
\mathrm{T}=2 \mathrm{P} / \pi l d
$$

Where:

$\mathrm{T}=$ splitting tensile strength, in $\mathrm{MPa},\left(\mathrm{N} / \mathrm{mm}^{2}\right)$;

$\mathrm{P}=$ maximum applied load indicated by the testing machine, in $\mathrm{N}$;

1 = length, in mm;

$\mathrm{d}=$ diameter, in $\mathrm{mm}$.

\subsection{Flexural Strength Test}

Flexural strength was conducted using the following formula in accordance to BSEN 12390-5:2009

$$
f_{d}=\frac{F \times I}{d_{1} \times d_{2}^{2}}
$$

Where:

$\mathrm{f}_{\mathrm{cf}}=$ flexural strength, in $\mathrm{MPa},\left(\mathrm{N} / \mathrm{mm}^{2}\right)$;

$\mathrm{F}=$ maximum load, in $\mathrm{N}$;

I $\quad=$ is the distance between the supporting rollers, in $\mathrm{mm}$;

$\mathrm{d} 1$ and $\mathrm{d} 2=$ diameter, in $\mathrm{mm}$.

\section{Results and Discussion}

\subsection{Physical Properties of KFPC}

Based on Fig 2 stated that the density of KFPC is much lower than the control sample of using OPC is $2420 \mathrm{~kg} / \mathrm{m}^{3}$ and PFA Concrete is $2342 \mathrm{~kg} / \mathrm{m}^{3}$. The density of control sample in accordance with practice BSEN 12390-7:2009. The contribution of fiber has decreased the unit weight of cube sample compared to plain sample. The $50 \mathrm{~mm}$ and $25 \mathrm{~mm}$ fiber length has filled the matrix of the composite, hence the density is lower. 


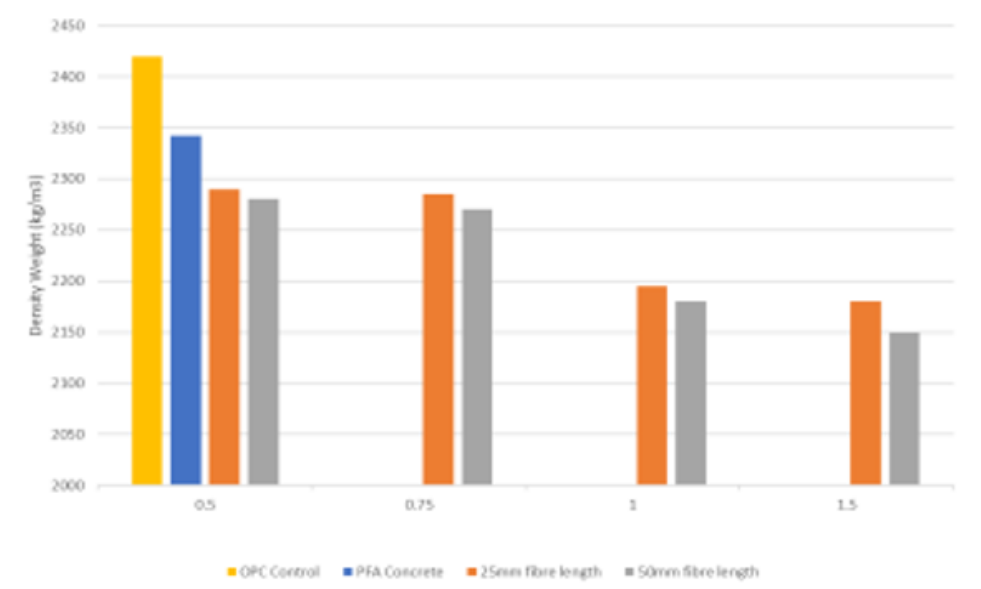

Fig. 2. The density of weight $(\mathrm{kg} / \mathrm{m} 3)$.

\subsection{Mechanical Properties of KFPC}

\subsubsection{Compressive Strength Results}

The compressive strength of KFPC is decreased than the normal concrete and PFA concrete as shown in figure 3. This is due to the behavior of fiber is not taking action on load compared to other mechanical properties. However, the compressive strength gradually increases with time 7 days, 28days and 56 days. PFA concrete is achieved the highest compressive strength of $26.38,38.57$ and $49.62 \mathrm{~N} / \mathrm{mm}^{2}$ on 7,28 and 56 days respectively. Normal concrete, however, achieved $27.09 \mathrm{~N} / \mathrm{mm}^{2}$ on 7 days and $45.87 \mathrm{~N} / \mathrm{mm}^{2}$ on 28 days but a bit lower on 56 days $48.50 \mathrm{~N} / \mathrm{mm} 2$ compared to PFA concrete. According to [8] the principles of pozzolanic action is increasing but depends on time and percentage of replacing. In this case, the $25 \%$ of PFA of replacing cement happened gradually and can achieve higher compressive strength than normal concrete.

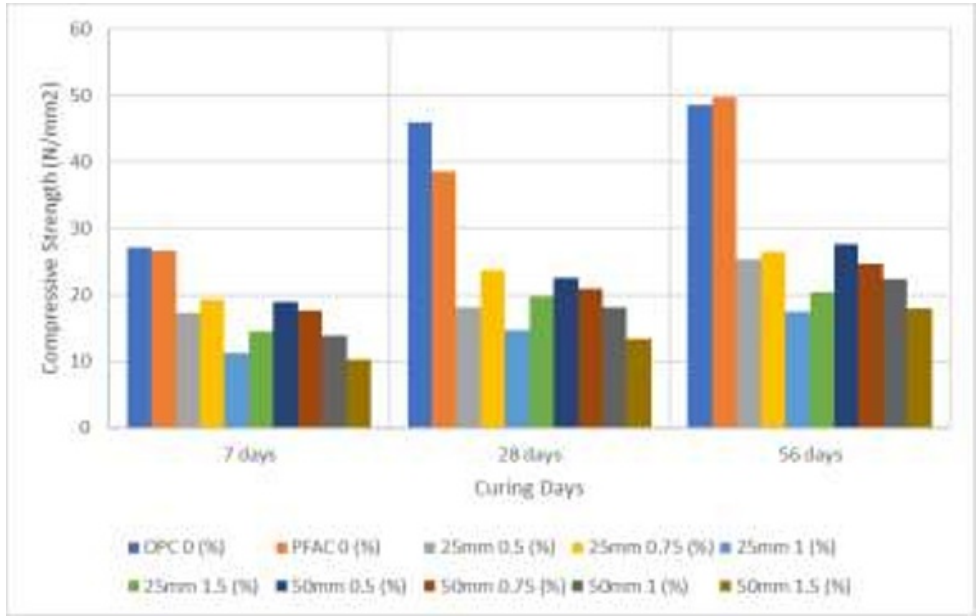

Fig. 3. Compressive Strength of KFPC (N/mm²). 


\subsubsection{Splitting Tensile Test Results}

Figure 4 shows that the tensile strength of KFPC shows the highest value of strength. The contribution of fiber shows the greater strength of this mechanical properties. The cylinder sample of KPFC was applied with a constant load at the side surface until it split as shown in fig 5. The strength at 56 days stated the highest value at $3.63 \mathrm{Nmm} 2$. All types of KFPC mix shows the increasing strength excluded at $1 \%$ and $1.5 \%$ range of fiber compared to normal and PFA concrete. The higher volume fraction of fiber decreases the value of strength. The range between $0.5 \%$ and $0.75 \%$ of fiber shows the suitability of fiber percentage in the concrete mix. The tensile behavior of fiber was strong in the concrete matrix to hold and carry loads.

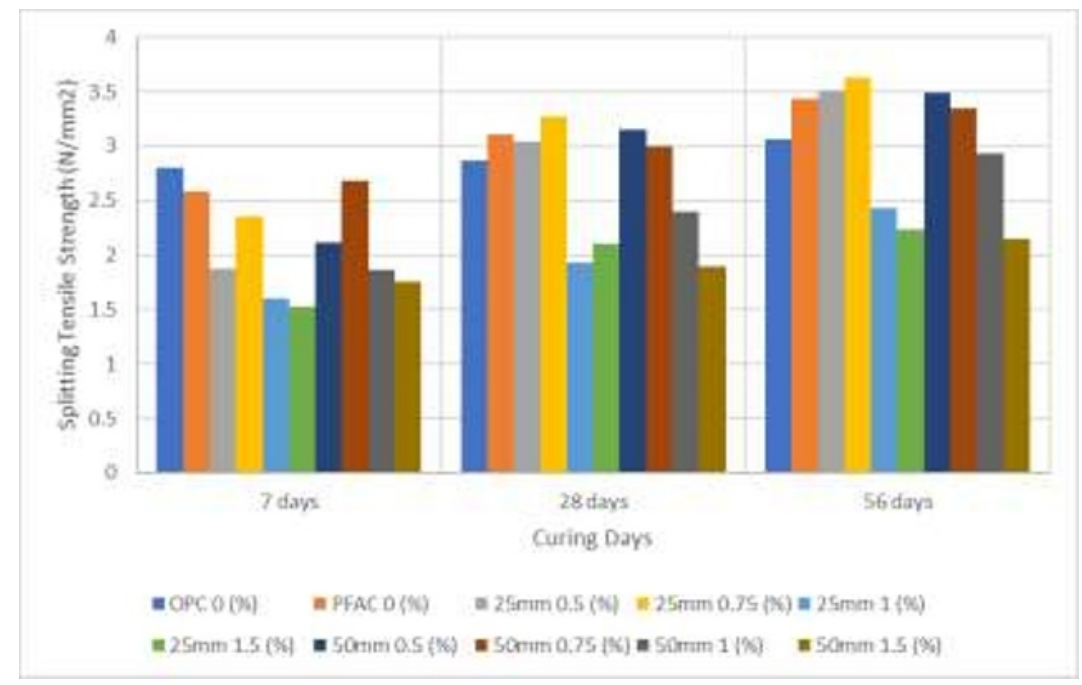

Fig. 4. Splitting Tensile Strength of KFPC $\left(\mathrm{N} / \mathrm{mm}^{2}\right)$.

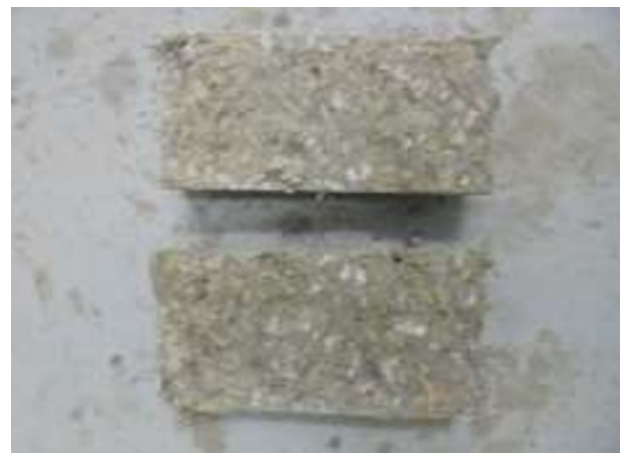

Fig. 5. Cylinder Sample of KFPC after testing.

\subsubsection{Flexural Test Results}

Figure 6 shows the $50 \mathrm{~mm}$ fiber length and $0.5 \%$ fiber volume fractions has great performance compared to other mixture of concrete. The value achieved $4.48 \mathrm{~N} / \mathrm{mm} 2$ and $4.76 \mathrm{~N} / \mathrm{mm}^{2}$ at 28 and 56 days respectively. Another mixture of concrete at $0.75 \%$ fiber volume fraction and $25 \mathrm{~mm}$ also shows the high value of strength at $4.46 \mathrm{~N} / \mathrm{mm} 2$ at 56 days. 
The development of fiber in PFA concrete increasing at 56 days because of pozzolanic action of PFA only happens if the $\mathrm{Ca}(\mathrm{OH})_{2}$ is enough to allow the hydration process. The $\mathrm{Ca}(\mathrm{OH})_{2}$ in a normal concrete happened at the early stage of curing. In the PFA concrete, replacement of cement affect the hydration process and because of that, the development of strength is taking a longer time.[9]

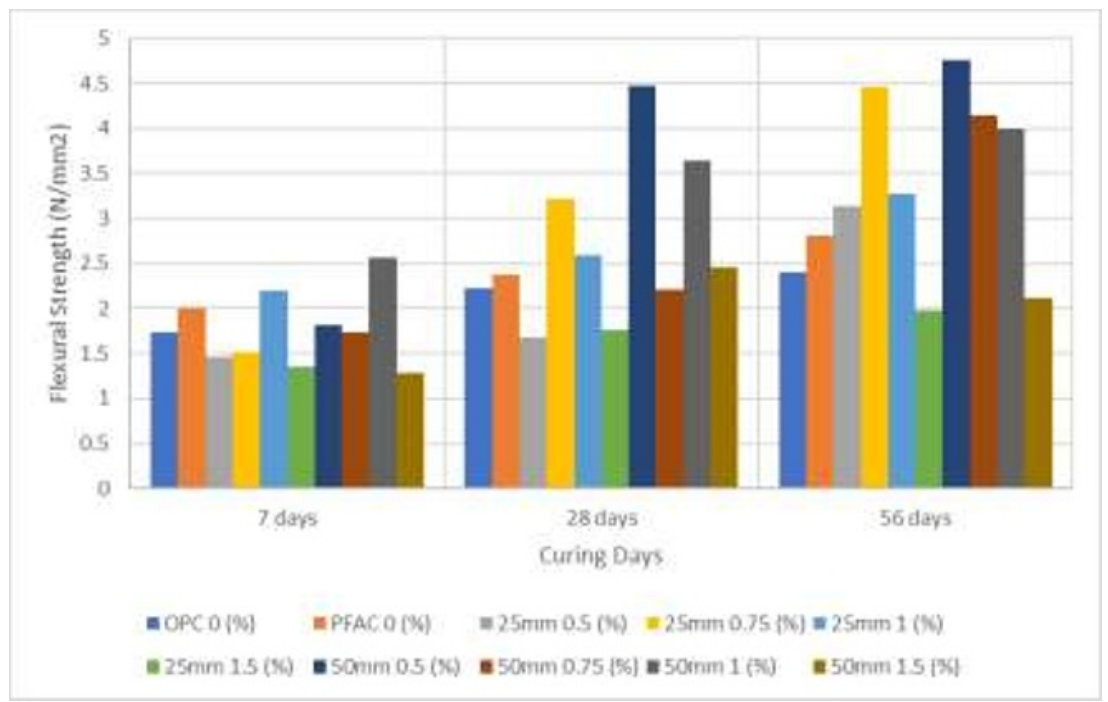

Fig. 6. Flexural Strength of KFPC $\left(\mathrm{N} / \mathrm{mm}^{2}\right)$.

\subsection{Effect of Kenaf Fiber with Pulverised Fuel Ash Concrete}

The inclusion of fiber has reduced the brittleness of normal and PFA concrete. Figure 7 shows that the cube sample of normal concrete, PFA concrete, Kenaf Fibrous Concrete (KPC) using OPC and Kenaf Fibrous Pulverised Fuel Ash Concrete (KFPC). The fiber has decreased the workability cause the hydrophilic action of fiber has absorbed moisture and water in the concrete mixture [1,10]. Hence, the addition of PFA slightly increase workability and pozzolanic action improves the tensile properties and bending action of concrete. The fiber holds the particles inside concrete and not brittle as it reaches the ultimate load.

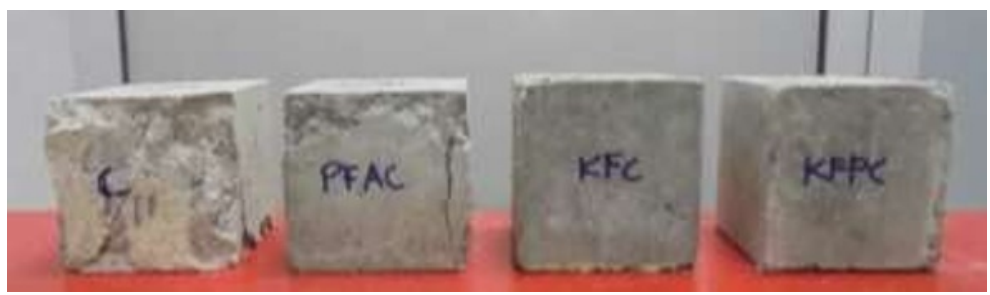

Fig. 7. Cylinder Sample of KFPC.

\section{Conclusion}

According to the results stated above, there are few conclusions that can be derived as follows; 
(1) Fiber volume fractions at $0.5 \%$ and $0.75 \%$ give good mechanical properties on splitting tensile and flexural strength.

(2) The addition of fiber and fly ash increase the strength and durability in a longer time compared to normal concrete.

(3) KFPC indicates to reduce cracking and ductility compared to normal concrete.

(4) KFPC has lower strength in compression, however higher strength in tensile and flexural strength. The orientation of fiber, fiber volume fraction and fiber length was indicated to find the optimum value of KFPC.

\section{References}

1. Hu, Z., Lee, J. W., Chandran, K., Kim, S., \& Khanal, S. K. (2012). Nitrous oxide (N2O) emission from aquaculture: A review. Environmental Science and Technology. https://doi.org/10.1021/es300110x

2. Kim, S., Dale, B. E., Drzal, L. T., \& Misra, M. (2008). Life Cycle Assessment of Kenaf Fiber Reinforced Biocomposite. Journal of Biobased Materials and Bioenergy, 2(1), 85-93. https://doi.org/10.1166/jbmb.2008.207

3. Uzal, B., \& Turanli, L. (2003). Studies on blended cements containing a high volume of natural pozzolans. Cement and Concrete Research, 33(11), 1777-1781. https://doi.org/10.1016/S0008-8846(03)00173-X

4. Naik TR, Moriconi G. Environmental friendly durable concrete made with recycled materials for sustainable concrete construction. In: Malhotra VM, Sakai K, editors. Sustainable development of cement, concrete and concrete structures, Proc. three-day intern. symp. Toronto, Canada; 2005. p. 485-505.

5. Mahjoub, R., Yatim, J. M., Mohd Sam, A. R., \& Hashemi, S. H. (2014). Tensile properties of kenaf fiber due to various conditions of chemical fiber surface modifications. Construction and Building Materials, 55, 103-113. https://doi.org/10.1016/j.conbuildmat.2014.01.036

6. Abubakar, A. U., \& Baharudin, K. S. (2012). Properties of concrete using Tanjung Bin power plant coal bottom ash and fly ash. International Journal of Sustainable Construction Engineering \& Technology, 3(2), 56-69.

7. ACI Committee 544, 1999. Measurement of Properties of Fiber Reinforced Concrete. ACI Structural Journal, 89(Reapproved), pp.1-12

8. A.M.Neville, J. J. B. (2010). Concrete Technology (Second Edi). London: Pearson Education Limited.

9. Wang, X.-Y., \& Park, K.-B. (2015). Analysis of compressive strength development of concrete containing high volume fly ash. Construction and Building Materials, 98, 810-819. https://doi.org/10.1016/j.conbuildmat.2015.08.099

10. Azzmi, N. M., \& Yatim, J. M. (2018). Kenaf Fibrous Concrete: Mechanical Properties with Different Fiber Volume Fraction. International Journal on Advanced Science, Engineering and Information Technology, 8(4), 1036-1042. 